\title{
MPPT of PV System Under Partial Shading Conditions Based on Bio-inspired Swarm Intelligence Technique
}

\author{
Mohammed Agdam ${ }^{1 *}$, Abdallah Asbayou ${ }^{1}$, Mustapha Elyaqouti ${ }^{1}$, Ahmed Ihlal ${ }^{1}$, Khaled Assalaou ${ }^{1}$ \\ ${ }^{1} \mathrm{~L}$ aboratory of $\mathrm{M}$ aterials and R enewable Energies U niversity I bn Zohr A gadir, M orocco
}

\begin{abstract}
To respond to the increase in demand for electricity, the use of photovoltaics is growing considerably as it produces electrical energy without polluting the environment. In addition, to enhance the efficiency of photovoltaic modules, an M PPT algorithm is required to follow the maximum voltage and maximum current in the IV curve. This technique can be achieved by using a DC-DC converter. For this purpose, various M PPT techniques have been developed. The combination of M PPT and DC-DC converter is implemented using M atlab/Simulink and connected to a modelled PV module to validate the simulation.
\end{abstract}

\section{Introduction}

At present, other research has concentrated on how to more effectively extract power from photovoltaic cells to raise the efficiency of solar photovoltaic systems. The main inconvenience of solar photovoltaic systems is the variability of the output voltage with variations in insolation and temperature. Maximum Power Point Tracking (MPPT) is a process that monitors a Maximum Power Point (MPP) of input to the photovoltaic (PV) array. The major goal of MPPT techniques is to find automatically the voltage VMPP or current IMPP at which a photovoltaic installation must work to achieve the maximum power MPPP under defined temperature and irradiance. It has been observed that in partially shaded conditions, the $\mathrm{P}-\mathrm{V}$ performance of the photovoltaic installation becomes more complex and carries multiple peaks [1]. There are numerous MPPT monitoring techniques in practice, and the comparison of most MPPT techniques to the power extracted from the PV panel has been proposed in the literature [2-3]. The most popular MPPT algorithms are Perturb and Observe (P\&O) and Incremental conductance (IC) algorithm. The author [4-5] compares and assesses the percentages of energy extraction with MPPT and with no MPPT. The various types of MPPTs have been introduced and developed. Fuzzy Logic is one of the suitable methods for getting the Maximum Power Point (MPP) of a solar panel that has excellent steadiness and a high answer rate. At present, the MPPT research [6-7] has been documented further because it is more efficient, precise and stable. In this paper, we present a survey of the basic characteristics of the PV cell and the circuit simulation model using Matlab/Simulink software. In addition, a very rugged controller using fuzzy logic is designed with the DC-DC boost converter in the Matlab/Simulink software to enhance the efficiency of the solar PV system [8-9].

\section{Photovoltaic System}

We take into consideration the PV system contains four sequences as shown in Figure 1. The first sequence represents the supply energy (photovoltaic panel), the second one is a DC-DC converter, the third sequence represents the charge and the last one represents the control system.

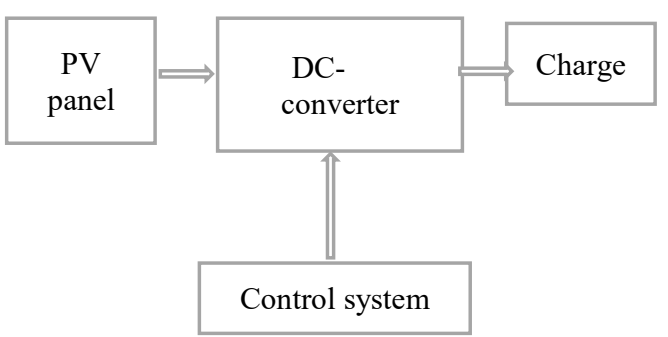

Fig. 1. Overview of the PV system

\subsection{Modelling of photovoltaic cell}

Figure 1 shows a single-diode model that is largely used compared to other PV module models. In this circuit, illustrates the equivalent circuit a PV cell, which was developed by [10]. This Figure shows the single diode model.

The corresponding equations of PV cell are as follows.

$\mathrm{I}_{\mathrm{pv}}=\mathrm{I}_{\mathrm{ph}}-\mathrm{I}_{\mathrm{d}}-\mathrm{I}_{\mathrm{sh}}$

The photocurrent $I_{p h}$ is given by the following equation:

$$
I_{p h}=\left(I_{c c}+K_{I}-\Delta \mathrm{T}\right) G / G_{n}
$$

\footnotetext{
* Corresponding author: mohammedagdam@gmail.com
} 
The current $I_{s h}$ crossing the shunt resistance is expressed by:

$$
I_{s h}=\frac{v_{p v}+I_{p v} R_{s}}{R_{p}}
$$

Diode current $I_{d}$ is given by:

$$
I_{d}=\mathrm{I}_{0}\left(\exp \left(\frac{V_{p v}+I_{p v} R_{S}}{\alpha V_{t}}\right)-1\right)
$$

Rsh is the shunt resistance, $\mathrm{I}_{\mathrm{pv}}$ is the open-circuit current of a solar cell, $I_{d}$ is the diode saturation current, Iph is the current generated by the light which varies according to solar radiation and cell temperature, Ish is the shunt resistance current flowing through the diode. Rsh and circulates between the $\mathrm{n}$ and $\mathrm{p}$ layers, Rs is the series resistance which represents the losses resulting from the flow of current through the emitter and the highly resistive contacts, $\mathrm{Vpv}$ is the terminal voltage of a solar cell, respectively.

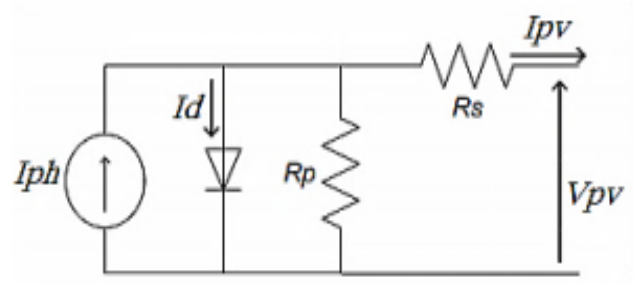

Fig. 1. Equivalent circuit PV cell

\subsection{Boost Converter}

The voltage of the solar panel is boosted by a step-up converter. It consists of an inductor, a capacitor, an IGBT/MOSFET and a diode. DC-DC converters are utilized to transfer the power from the solar panel to the load side, guaranteeing that the maximum power has been transferred, using MPPT. Regulation is realised by pulse width modulation (PWM) and the switching device is a MOSFET or IGBT. DC-CD Boost converters whose function is to boost the DC voltage. Maximum power is attained when the MPPT algorithm changes and adjusts the duty cycle of the DC-DC Boost converter. The circuit diagram is described Fig2:

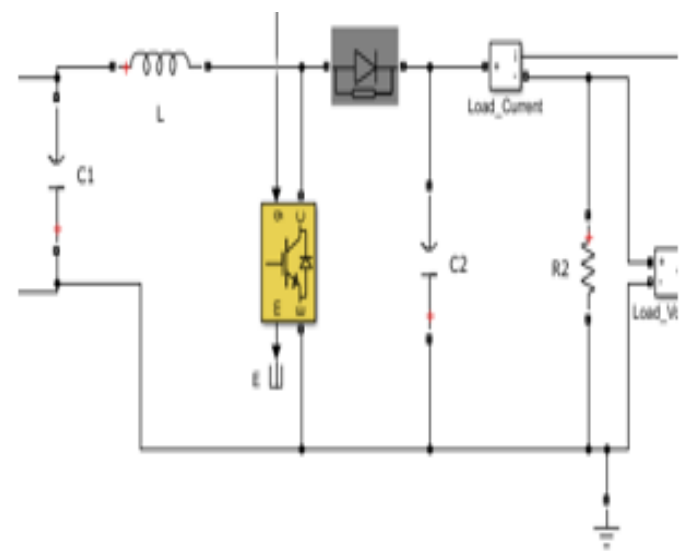

Fig. 2. Simulink model of DC-DC boost converter.

The design value for DC-DC boost converter are, inductor(L) value is $3 \mathrm{mH}$, input and output capacitor
(C1 and $\mathrm{C} 2$ ) value is $100 \mu \mathrm{F}$ and switching frequency of the converter is $10 \mathrm{kHz}$.

\subsection{Partial shaded PV Model}

The total 60 solar pv cell is divided in to three models and each model has 20 cells. The 20 cell model is rated by following parameter, the open circuit voltage is 12.64 volts, voltage at maximum power is 10.32 volts, short circuit current is $8.62 \mathrm{~A}$ and current at maximum power point is 8.07 and maximum power point is 83.2824Watts. This three model is connected in series and each model has bypass diode. The Simulink model of the three series connected solar PV system is shown in Figure 3.

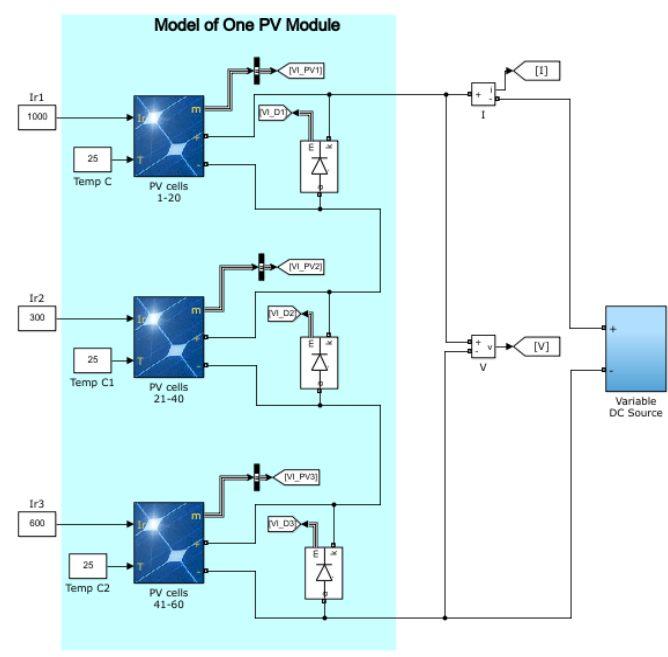

Fig. 3. Three series connected solar PV system

The partial shaded condition of solar PV model is created by making irradiance of each model at different value such as $1000 \mathrm{~W} / \mathrm{m} 2$ is fixed for panel $1,300 \mathrm{~W} / \mathrm{m} 2$ for panel 2 and $600 \mathrm{~W} / \mathrm{m} 2$ for panel 3. The IV and PV characteristics of the partial shaded conditions are shown in Figure 4:
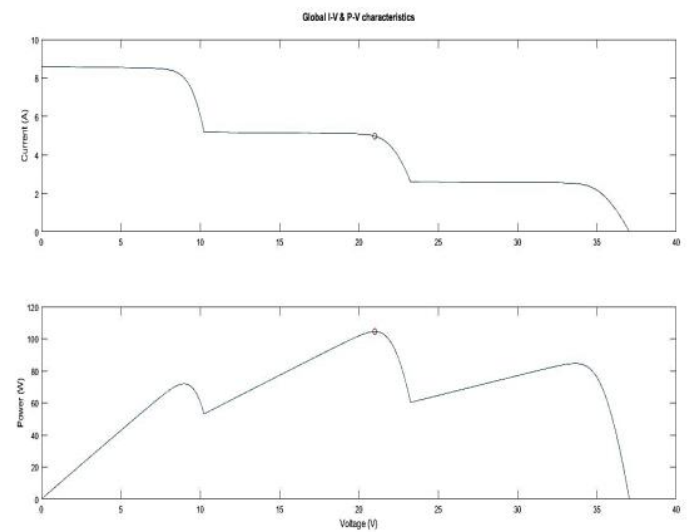

Fig. 4. The IV and PV characteristics of the partial shaded conditions

\section{MPP technique}

We understand that photovoltaic solar modules have changing parameters when the operating temperature 
and radiation vary. The parameters for which a fluctuation is noted are maximum power, maximum voltage, open circuit voltage, maximum power current and short-circuit current. MPPT suggested algorithm applied to the DC-DC converter to extract the maximum power available at the under-variation of the solar PV module output in operating temperature and irradiance.

\subsection{Perturb \& Observe}

The P\&O method is based on disturbances applied to the reference voltage or current signal, and is one of the most widely used methods for MPPT [11- 12].

The flowchart in Figure 5 shows the P\&O algorithm such that, to calculate the power value $\mathrm{P}(\mathrm{k})$, the current Ipv and voltage Vpv must be measured. If the power value $\mathrm{P}(\mathrm{k})$ is higher than the previously measured $\mathrm{P}(\mathrm{k}$ 1), the PPM is approximated. The disturbance will continue in the same direction. If the power value $\mathrm{P}(\mathrm{k})$ is lower than the previously measured $\mathrm{P}(\mathrm{k}-1)$, MPP is away, so the disturbance will be reversed in the inverse direction.

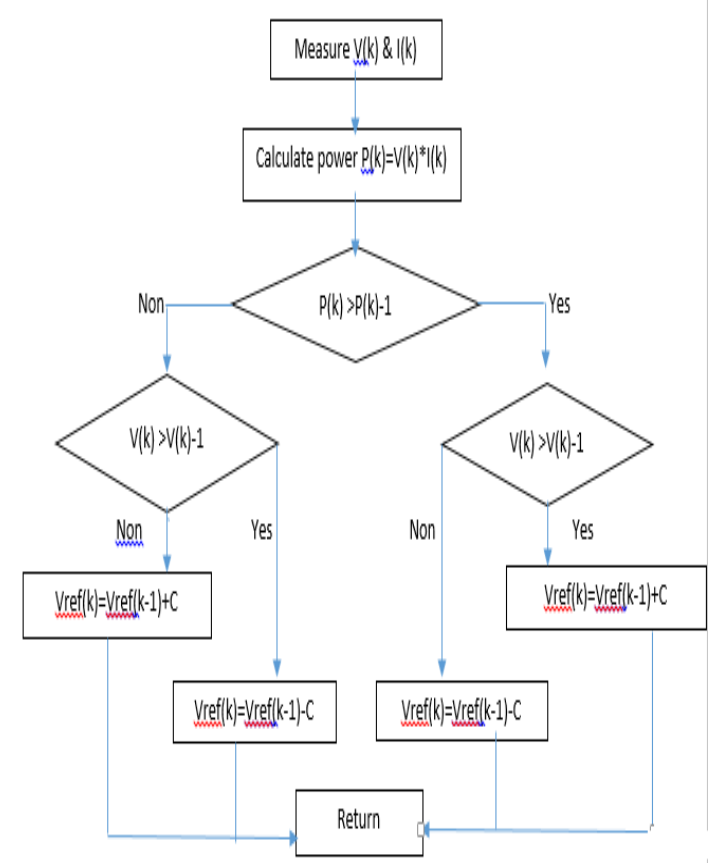

Fig.5.Flowchart of the "P\&O" algorithm

\subsection{Particale swarm optimization}

PSO, as a new swarm intelligence optimization algorithm, firstly proposed by Kennedy and Eberhart [13], has been developing rapidly in recent 20 years. It is modelled according to the behaviour of bird flocks. Its advantages are simple realization and fast convergence, and it is well applied to find the global optimal solution in a nonlinear, discontinuous, non-differentiable curve. In this algorithm, several cooperative particles are used in an $\mathrm{n}$ dimensional space. Each particle owns its position $\mathrm{Pi}$ (distributed randomly) and velocity $\mathrm{Vi}(\mathrm{Vi}=$ 0 in initiation). The position of a particle is influenced by its best position so far, Pbest, and the best position of all particles so far, Gbest. Velocity and position of particles are calculated by [14.15.16]:

$$
\begin{gathered}
v_{i}^{k+1}=\omega v_{i}^{k}+c_{1} r_{1}\left(P_{b e s t i}-P_{i}^{k}\right)+c_{2} r_{2}\left(G_{\text {besti }}-P_{i}^{k}\right) \\
P_{i}^{k+1}=P_{i}^{k}+v_{i}^{k+1}
\end{gathered}
$$

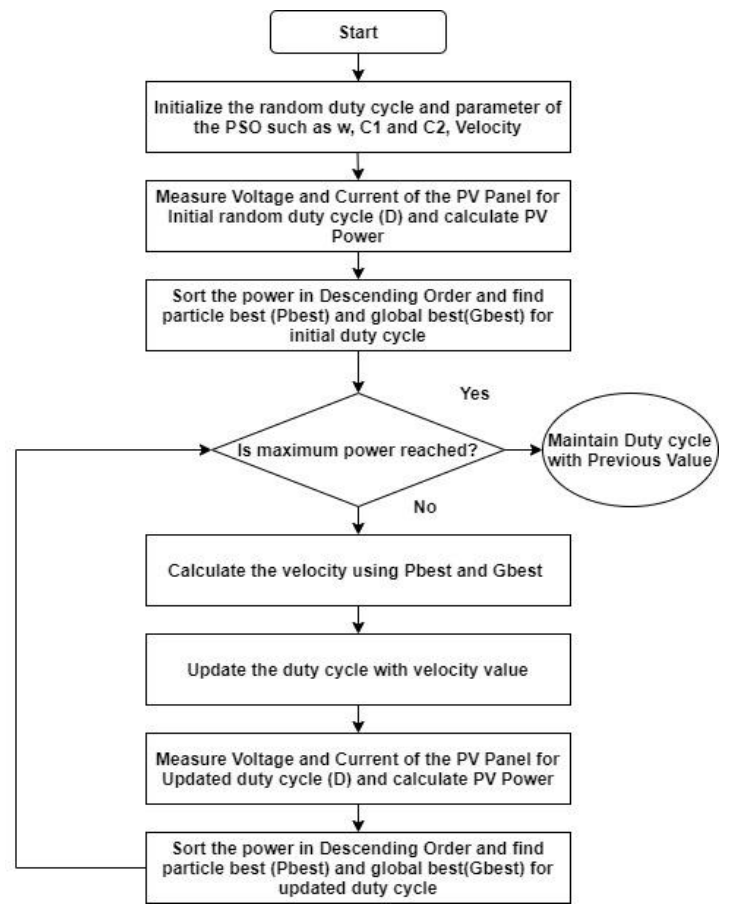

Fig.6. Flowchart of PSO algorithm

\subsection{Grey Wolf Optimizer}

It imitates the pyramid of leadership and the chasing method of grey wolves in nature suggested by [17] et al. To simulate the leadership hierarchy, four different styles of grey wolves are used, such as alpha, beta, delta and omega. When developing GWO, alpha is taken as the fittest approach. The second and third best options are beta and delta, and the remaining wolves are known as omega. By surrounding the target, grey wolves chase the prey, and the encircling action is modelled by the following equations:

$$
\begin{aligned}
& \overrightarrow{\boldsymbol{D}}_{=\mid} \overrightarrow{\boldsymbol{C}} \cdot \overrightarrow{\boldsymbol{X}}_{\mathrm{P}(t)}-\overrightarrow{\boldsymbol{X}}_{\mathrm{P}(t) \mid} \\
& \overrightarrow{\boldsymbol{X}}_{\mathrm{P}(t+1)=} \overrightarrow{\boldsymbol{X}}_{\mathrm{P}(t)}-\overrightarrow{\boldsymbol{A}} \cdot \overrightarrow{\boldsymbol{D}}
\end{aligned}
$$

$\mathrm{D}, \mathrm{A}$ and $\mathrm{C}$ represent coefficient vectors, where $\mathrm{t}$ denotes the current iteration, $\mathrm{Xp}$ is the prey's position vector and $\mathrm{X}$ implies the grey wolf's position vector. The $\mathrm{A}$ and $\mathrm{C}$ vectors are determined as follows:

$$
\begin{aligned}
& \overrightarrow{\boldsymbol{A}}=2 \cdot \overrightarrow{\boldsymbol{a}} \cdot \overrightarrow{\boldsymbol{r}}_{1}-\overrightarrow{\boldsymbol{a}} \\
& \overrightarrow{\boldsymbol{C}}=\mathbf{2} \cdot \overrightarrow{\boldsymbol{r}}_{2}
\end{aligned}
$$

Where components of "a" are linearly decreased from 2 to 0 over the course of iterations and $\mathrm{r} 1, \mathrm{r} 2$ are random vectors in $[0,1]$. 


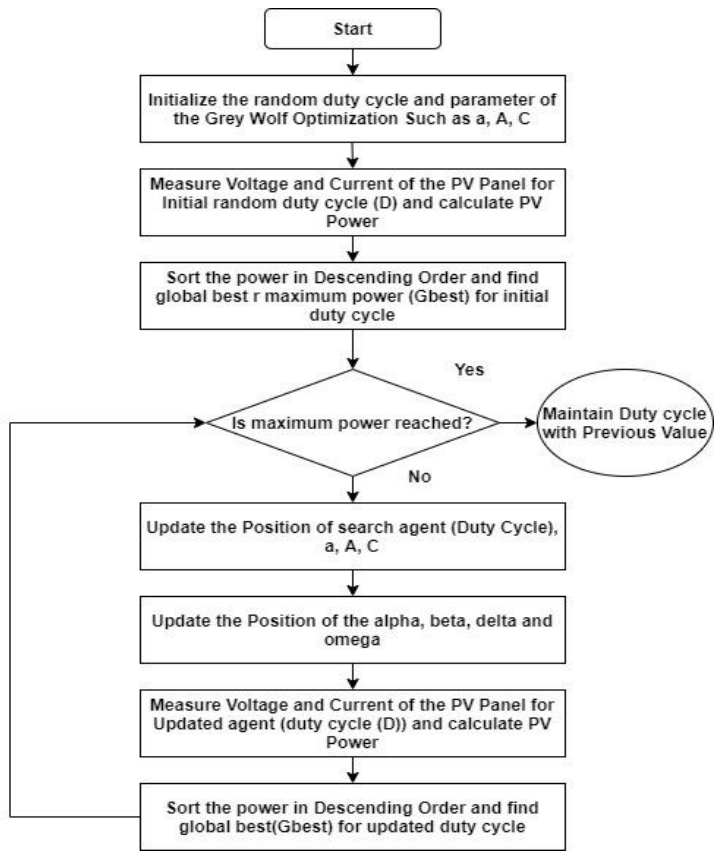

Fig.7.Flowchart of grey wolf MPPT

\section{Analyse and discussion of the results}

For analysing the tracking performances of PSO and GWO-based trackers and compare them with the conventional one, $\mathrm{P} \& \mathrm{O}$ technique, extensive MATLAB simulation studies under PSC patterns have been performed. PV module is chosen to be used in the simulation model is illustrate in table. The PV system illustrated by Fig. 8 consists of three series-connected modules and DC/DC boost converter. The design value for DC-DC boost converter are, inductor(L) value is 3 $\mathrm{mH}$, input and output capacitor $(\mathrm{C} 1$ and $\mathrm{C} 2$ ) value is 100 $\mu \mathrm{F}$ and switching frequency of the converter is $10 \mathrm{kHz}$. The operating scenario of the system shown in Fig. 4 was based on sensing shaded PVPS voltage and current which are fed to MPPT block to search duty cycle at which global maximum power can be derived.

Table. Parameters of the electrical characteristics of the single PV.

\begin{tabular}{|c|c|}
\hline Type panel & Style \\
\hline $\begin{array}{c}\text { Voltage at } \\
\text { maximum power }\end{array}$ & $10.32 \mathrm{~V}$ \\
\hline $\begin{array}{c}\text { Current at } \\
\text { maximum power }\end{array}$ & $8.07 \mathrm{~A}$ \\
\hline $\begin{array}{c}\text { Open - Circuit } \\
\text { Voltage }\end{array}$ & $12.64 \mathrm{~V}$ \\
\hline $\begin{array}{c}\text { Short - Circuit } \\
\text { Current }\end{array}$ & $8.62 \mathrm{~A}$ \\
\hline $\begin{array}{c}\text { Maximum Power } \\
\text { at STC }\end{array}$ & $104 \mathrm{~W}$ \\
\hline
\end{tabular}

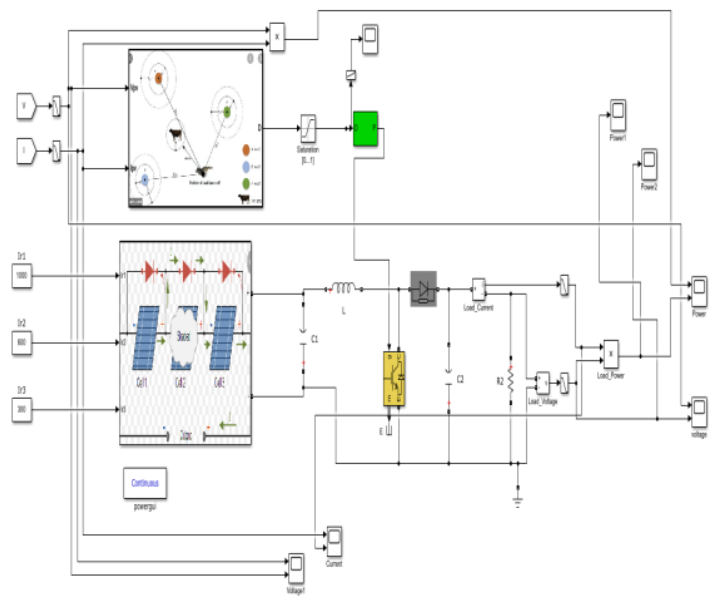

Fig.8. PV system under MATLAB/Simulink

Three different MPPT techniques were employed as a controller feeding the converter with an appropriate duty cycle to study and compare the dynamic response of the PVPS during PSC.

The simulation details (power, voltage, and duty cycle of the boost converter) of PVPS with different MPPT techniques under the shading model are illustrated in Figure 9, 10, 11,12,13,14, As indicated in Figure 15, 16, 17, the PSO and GWO,P\&O trackers start the initialization by setting the duty cycles of the boost converter to $0,0.7$ respectively, to guarantee that the search space covers the whole P-V curve. Then the duty cycle values are changed. Then the duty cycle values are changed. This process continues until the termination criterion is reached. GWO, PSO and P\&O converge to the global PPM with a tracking time of $0.9 \mathrm{~s}, 1 \mathrm{~s}$ and $1.4 \mathrm{~s}$ respectively.

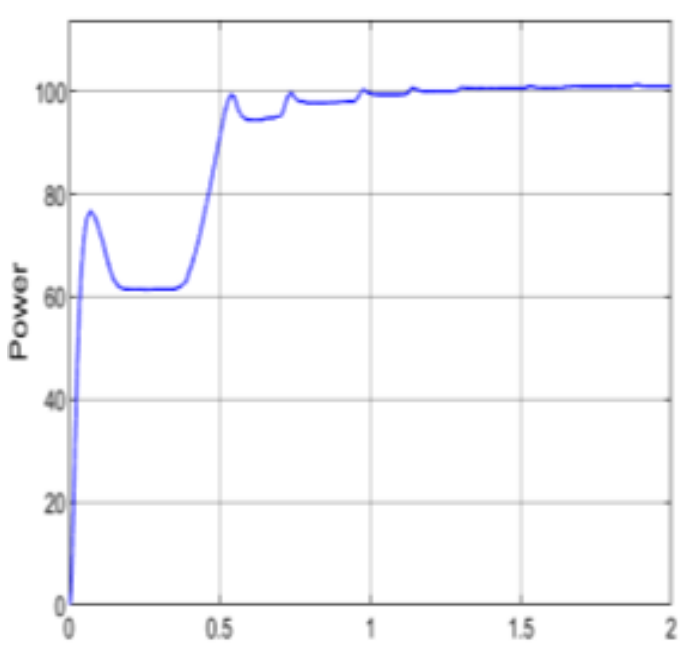

Fig.9.P\&O-based tracker MPPT 


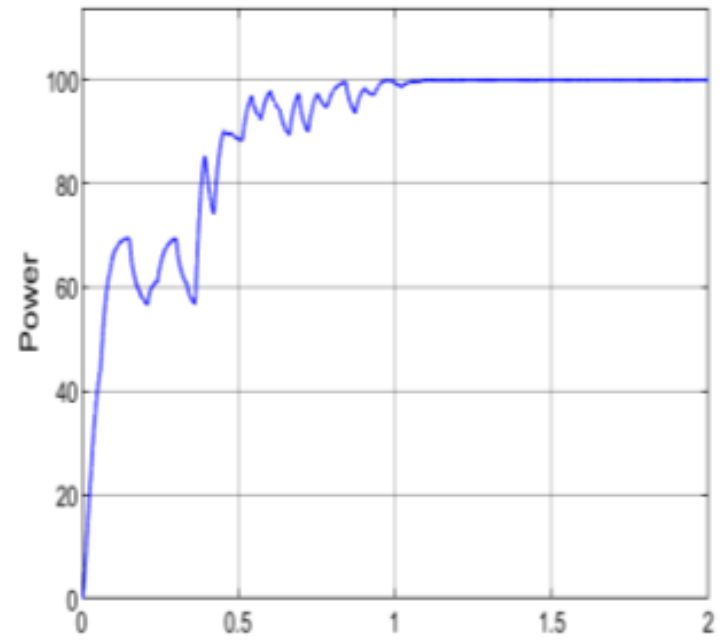

Fig.10. PSO-based tracker

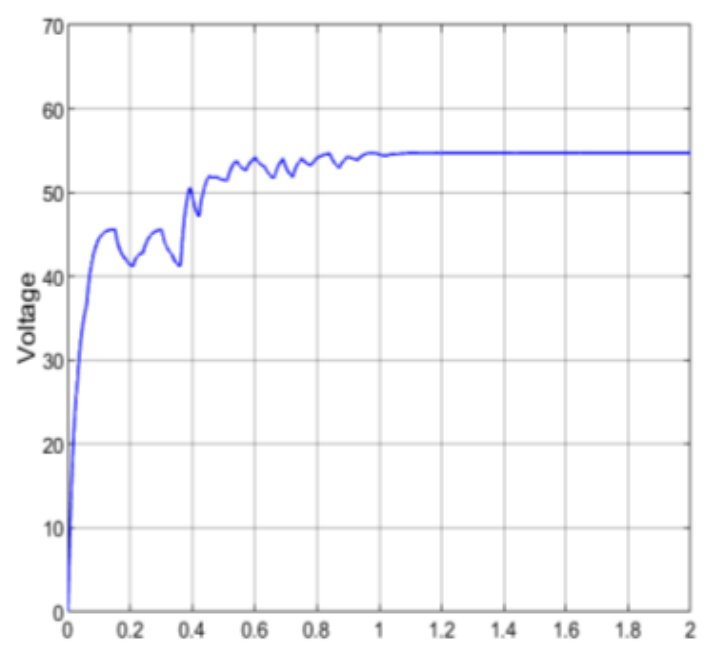

Fig.12. PSO-based tracker

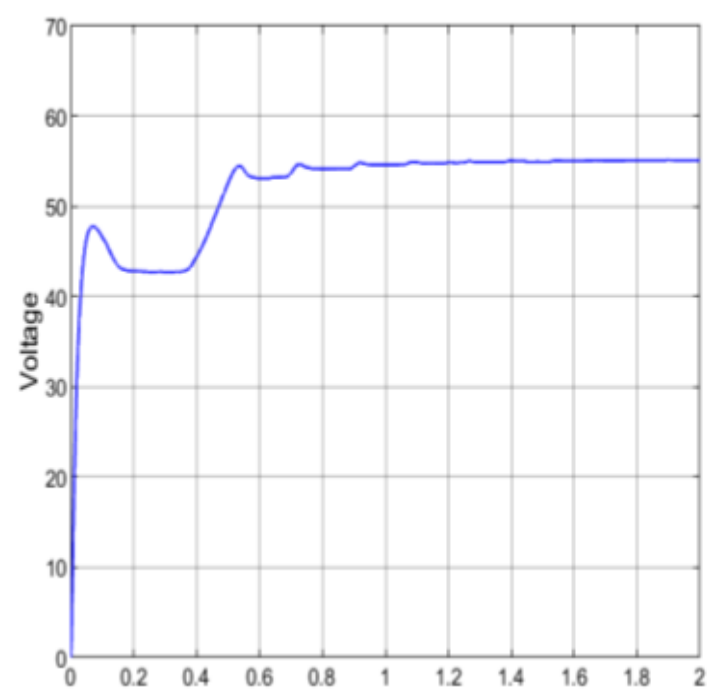

Fig.14. P\&O-based tracker

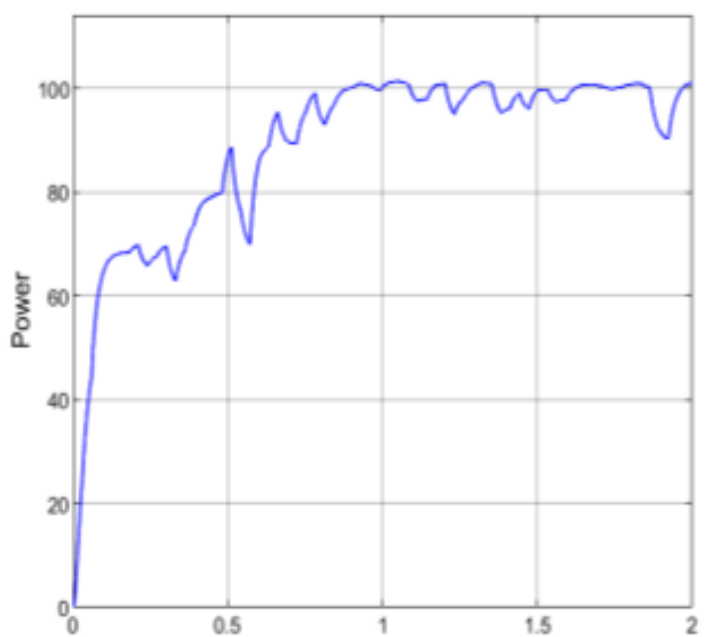

Fig.11. GWO-based tracker

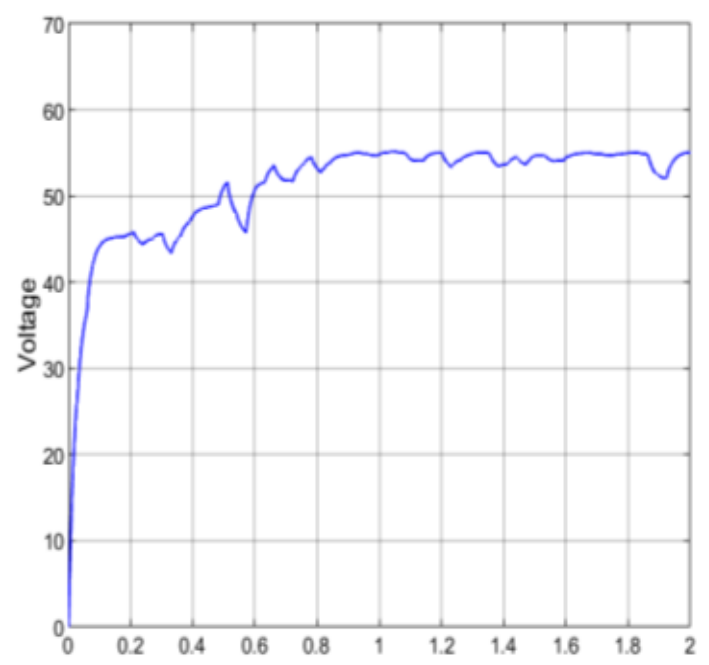

Fig.13. GWO-based tracker

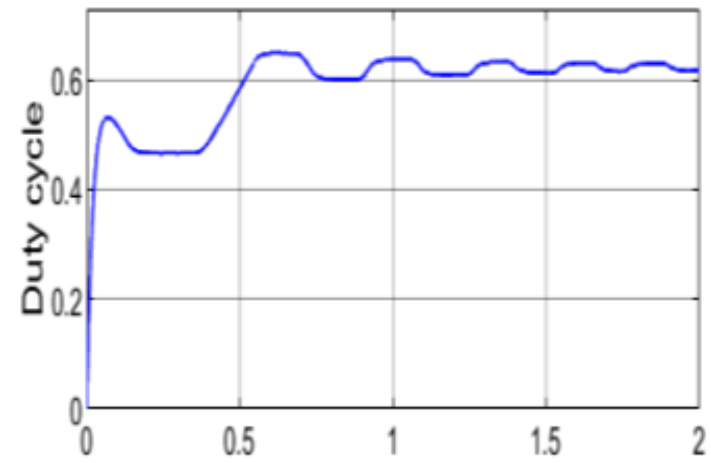

Fig.15. P\&O-based tracker

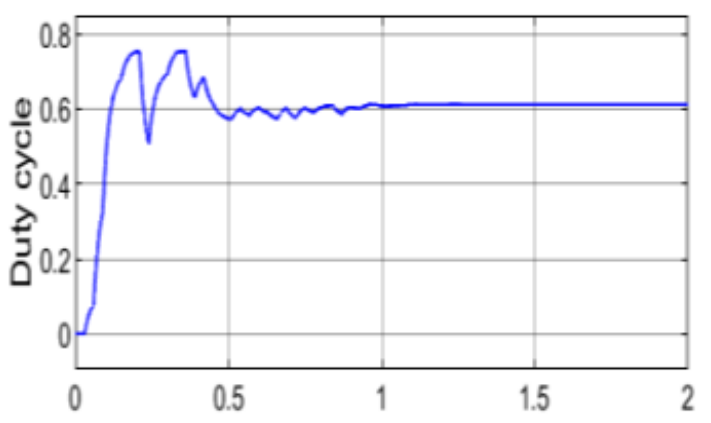

Fig.16. PSO-based tracker 


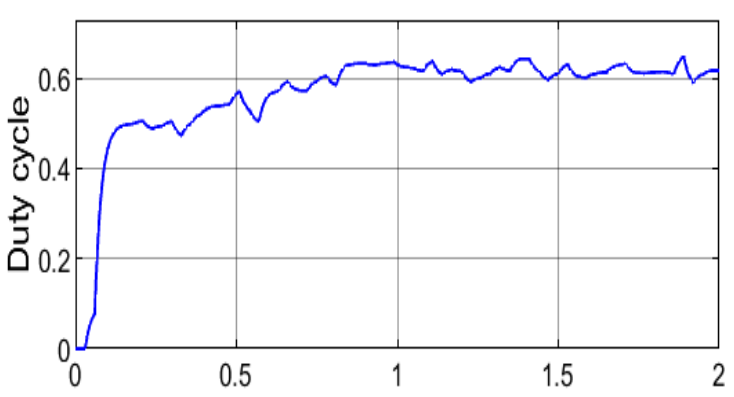

Fig.17. GWO-based tracker

\section{Conclusion}

The performance of two global MPPT based on metaheuristic optimization algorithms is evaluated. Such algorithms include; PSO and GWO techniques. The presented algorithms aim to improve the efficiency of partially shaded PVPS. The proposed algorithms target the improvement of the efficiency of partially shaded photovoltaic systems.

From this result we can be deduced that the two technique MPPT control gives good results compared to control $\mathrm{P} \& \mathrm{O}$ in terms of response time and the point of maximum power (PPM). When parameters like output voltage, power are compared.

The entire photovoltaic system was simulated on the based on Meta-heuristic (PSO,GWO) MPPT algorithm and the results of the simulation were verified. It is clearly shown that the PV system achieves good efficiency when a bio-inspired techniques MPPT controller is used in the system. In the future, the model designed can be implemented in hardware using microcontrollers.

\section{References}

1. T. Esram and P. L.Chapman, IEEE Trans. Energy Convers., 22, 2, 439-449, (2007).

2. K. I shaque and Z. Salam, Renew. Sustain. E nergy Rev., 19, 475-488, (2013).

3. L. Liqun, $X$. M eng, and C. Liu. Renew. Sustain. Energy Rev, 53, 1500-1507, (2016).

4. A. Kouchaki, H. Iman-Eini, and B. A saei, Solar Energy, 91, 221-232, (2013)

5. R. C. Pilawa-Podgurski and D. J. Perreault, IEEE Trans. Power Electron., 28, 6, 2957-2967, (2013).

6. C. W oei-L uen and C. Tsai. IEEE Trans. Ind. Electron., 62, 8, 4837-4848, (2015).

7. K. Ishaque, Z. Salam, M. A mjad, and S. M ekhilef, IEEE Trans. Power Electron., 27,8, 36273638,(2012).

8. Cheikh M. S. A., Larbes C., Kebir G. F. T. and Zerguerras, Revue des Energies R enouvelables, $10,32,(2007)$

9. Sofai. Lalouni, Djamila. Rekioua, , IEEE International Conference on Developments in Systems Engineering, (2009).
10. M. Gradella V illalva, J. Rafael Gazoli, E. Ruppert Filho, IEEE Transactions on Power Electronics, 24, 5 ,1198-1208.( 2009)

11. T. T afticht, K. A gbossou, M .L. Doumbia, A. Cherita, Renew. Energy 33,1508-1516. (2008).

12. K.H. Hussein, I. M uta, T. Hoshino, M. Osakada. IEE Proceedings - Generation, Transmission and Distribution, 142, 59-64. (1995)

13. Eberhart, R., \& K ennedy, J . n Proceedings of the IEEE international conference on neural networks, 4,1942-1948,(1995)

14. S.M. M irhassaniet, S.Z. Golroodbari, S.M. Golroo dbari, S. M ekhilef ,EPES, 64 , 761-770, (2015)

15. N. B outasseta, Int J Comput A ppl, 48 (17), 3640 (2012)

16. K. Ishaque, Z. Salam, IEEE Trans Ind Electron, 60 (8), 3195-3205, (2013)

17. Seyedali M irjalili , Seyed M ohammad M irjalili ,A ndrew Lewis,A ES , 69, 46-61,(2014) 